\title{
DESEMPENHO DE CLASSIFICADORES SUPERVISIONADOS PARA A DINÂMICA DA ÁREA DE INUNDAÇÃO DA UHE TELES PIRES
}

Ana Paula Marques Martins ${ }^{1}$, Natália Peixoto Gaiad ${ }^{2}$, Aline Bernarda Debastiani ${ }^{1}$, Ana Paula Dalla Corte ${ }^{3}$, Carlos Roberto Sanquetta ${ }^{3}$

1 Doutoranda em Engenharia Florestal, Universidade Federal do Paraná, Curitiba, PR, Brasil. anapaulamartins503@gmail.com

2 Mestranda em Engenharia Florestal, Universidade Federal do Paraná, Curitiba, PR, Brasil.

3 Professor do Departamento de Engenharia Florestal, Universidade Federal do Paraná, Curitiba, PR, Brasil.

Recebido em: 08/04/2017 - Aprovado em: 10/06/2017 - Publicado em: 20/06/2017 DOI: 10.18677/EnciBio_2017A35

\section{RESUMO}

O objetivo dessa pesquisa foi avaliar o desempenho de cinco classificadores digitais de imagens, assim como realizar a análise multitemporal, entre os anos de 2006 e 2015, de uma área de influência de alagamento da Usina Hidrelétrica Teles Pires que fica na divisa dos Estados de Mato Grosso e Pará. Para tanto, foram adquiridas imagens do satélite Landsat 5-TM e Landsat 8-OLI da área de estudo para o mesmo período do ano. Foram utilizadas as bandas MultiSpectrais com mesma resolução espacial de 30 metros e avaliados os classificadores: máxima verossimilhança, paralelepípedo, distância mínima, redes neurais artificiais e support vector machine. Os classificadores distância mínima e redes neurais artificiais foram os algoritmos que propiciaram os melhores resultados, sendo selecionado a classificação gerada pela distância mínima para a análise multitemporal. Em 2015, pós-inundação, a área classificada como água obteve um aumento de mais de $138 \%$ em relação à área existente em 2006, sendo floresta a classe mais afetada.

PALAVRAS-CHAVE: Kappa, satélite Landsat, uso e cobertura da terra.

\section{PERFORMANCE OF SUPERVISED CLASSIFIERS FOR THE DYNAMIC FLOOD AREA OF UHE TELES PIRES}

\begin{abstract}
The objective of this research was to compare different classifiers, as well as perform multitemporal analysis, between 2006 and 2015, a flooding area of influence of the hydroelectric plant Teles Pires localized in the border of Mato Grosso and Pará states. Therefore a satellite image Landsat 5-TM and other Landsat 8-OLI area the same period last year were acquired. The multispectral bands with the same spatial resolution of 30 meters were used. They were evaluated classifiers: maximum likelihood, parallelepiped, minimum distance, artificial neural networks and support vector machine. The minimum distance classifiers and neural networks are algorithms that provided the best results, being selected the classification generated by the minimum distance for multi-temporal analysis. In 2015, post-flood, the area
\end{abstract}


classified as water obtained an increase of over $138 \%$ compared to the existing area in 2006, being the most affected forest class.

KEYWORDS: Kappa, satellite Landsat, use and land cover.

\section{INTRODUÇÃO}

A utilização crescente de energia pelo homem moderno é irreversível devido aos avanços tecnológicos, e a principal fonte de geração de energia utilizada no Brasil são as usinas hidrelétricas. Contudo, a implantação e operação dessas usinas podem trazer problemas ambientais e sociais que ultrapassam a região onde estão localizados esses empreendimentos (SIQUEIRA LIMA \& TEXEIRA BATISTA, 2010).

Segundo MESSIAS et al. (2012), dentre as alterações provocadas pela ação antrópica, a construção de usinas hidrelétricas encontra-se entre uma das alterações mais significativas e atuam como um dos agentes modificadores da paisagem causando diversos impactos ambientais, econômicos e culturais. Diante disso, o conhecimento das características dos locais onde se realizam significativas mudanças no meio ambiente, assim como das potencialidades e limites naturais desses empreendimentos, é de suma importância (MESSIAS et al., 2012).

Nesse contexto, o sensoriamento remoto contribui como uma importante ferramenta para detecção das alterações do uso e cobertura da terra, contribuindo para quantificar as tendências e as intensidades dos processos de mudanças nessas unidades (ROSA DE PAULA, 2012). Então, a classificação de dados de sensoriamento remoto é uma das informações, com confiabilidade e rapidez, que possibilita uma melhor gestão de terras nas áreas afetadas por alterações antrópicas drásticas, como é o caso das usinas hidrelétricas.

A importância do conhecimento do uso e cobertura da terra quando se constrói uma usina hidrelétrica é imprescindível, por questões da valoração da mudança do uso da terra e da alocação dos proprietários e populações vizinhas, esses que são prejudicados pela alteração do local. Dessa forma, LEITE et al. (2015) afirmam que quando se fala em impactos causados pela construção de barragens, é importante salientar que esses podem ser de caráter positivo ou negativo. Ao analisar a construção de uma barragem, é necessário levar em consideração a compensação de sua instalação, considerando os benefícios e malefícios provocados por esta.

Diante do exposto, o objetivo dessa pesquisa foi avaliar o desempenho de cinco classificadores digitais de imagens e analisar o comportamento do uso da terra entre os anos de 2006 e 2015, por meio de uma análise multitemporal em uma área alterada por influência da construção da barragem da Usina Hidrelétrica (UHE) Teles Pires.

\section{MATERIAL E MÉTODOS}

\section{Área de estudo}

A área de estudo corresponde à área de influência de alagamento da barragem da Usina Hidrelétrica (UHE) Teles Pires, localizada na região do médio Teles Pires, na divisa dos Estados de Mato Grosso e Pará, a 330 km de distância da junção com o Rio Juruena, ponto onde se forma o Rio Tapajós (Figura 1) (RIMA UHE TELES PIRES, 2010). 

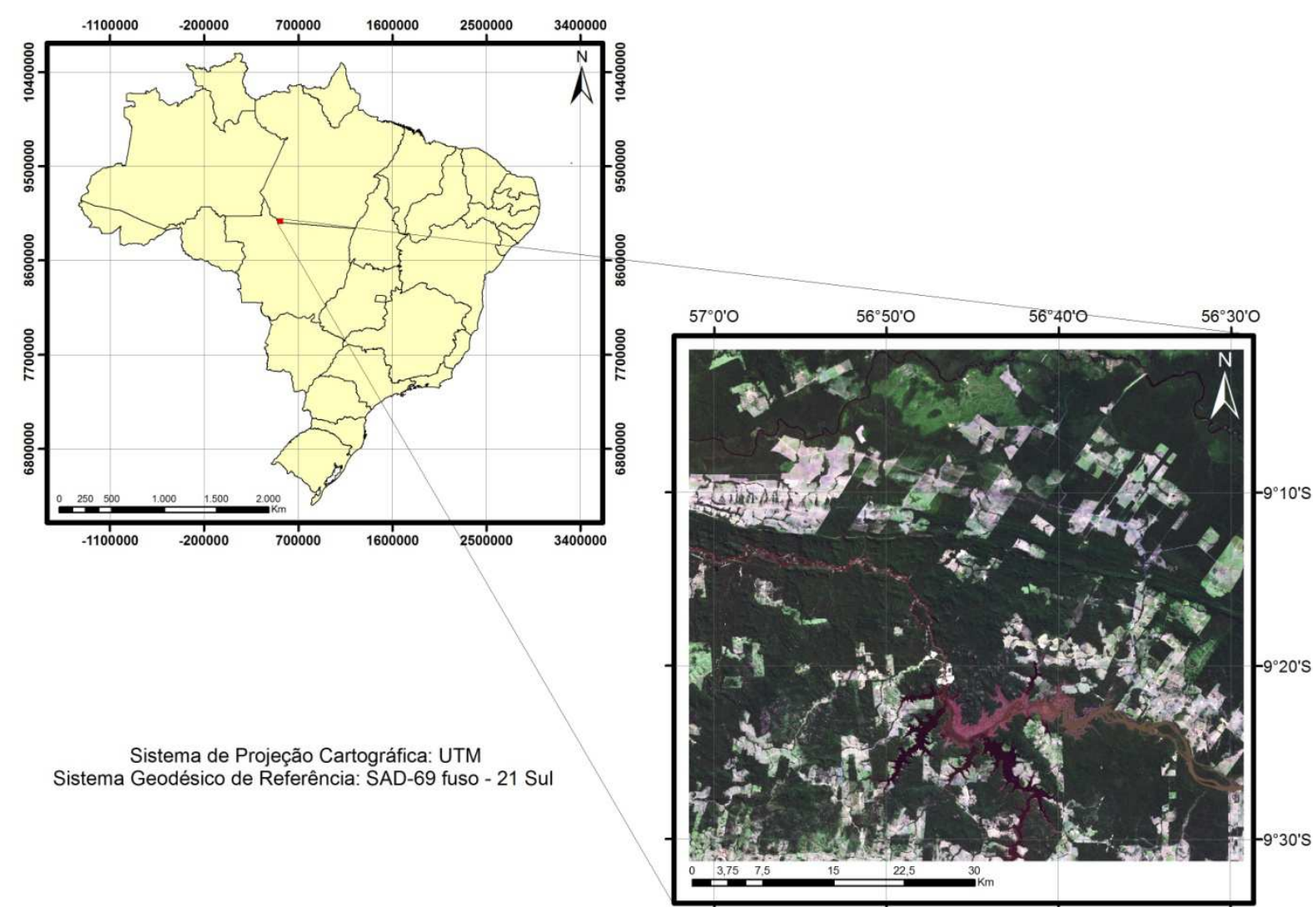

FIGURA 1 - Localização da área de estudo.

FONTE: Os autores (2016)

As obras da UHE Teles Pires começaram no dia 22 de agosto de 2011, sendo que a Licença de Istalação (LI) da mesma foi aprovada pelo Instituto Brasileiro do Meio Ambiente e dos Recursos Naturais Renováveis - IBAMA no dia 19 de agosto de 2011 (UHE TELES PIRES, 2016). Esta área foi escolhida motivada pelo interesse em conhecer as alterações sofridas quando há uma interferência antrópica na paisagem ocasionada pela implantação de uma Usina Hidrelétrica, quantificando suas mudanças.

\section{Aquisição de dados e processamento}

Foi adquirida junto a plataforma do Instituto Nacional de Pesquisas Espaciais - INPE (http://www.inpe.br/) uma imagem do satélite Landsat 5 e outra Landsat 8 abrangendo a área de estudo (órbita 228 e ponto 66).

A imagem escolhida do satélite Landsat 5, sensor TM (Thematic mapper), é datada de 27 de julho de 2006 servindo como base para retratar a área antes da construção da barragem. Foi escolhida uma imagem do Landsat 8 (sensor OLI Operational Land Imager), para o mesmo período (20 de julho de 2015), para retratar a imagem após a construção da barragem.

As imagens foram georreferenciadas com base na carta topográfica "Córrego da Perdição" MT-PA, folha SC 21-X-C-I-MI-1483, na escala 1:100.000 com projeção cartográfica UTM e sistema geodésico de referência SAD-69 fuso 21 Sul. Todas as etapas do processamento foram realizadas com ou auxílio do programa Envi versão 5.2 . 


\section{Classificação de imagens}

Para obtenção do mapa de uso e cobertura da terra por classificação supervisionada foi necessário coletar amostras referentes a cada classe de uso, tais como, floresta, água, vegetação rasteira e solo exposto, essas para a realização da classificação.

Os métodos de classificação supervisionada foram Paralelepípedo, Distância Mínima (DM), Máxima Verossimilhança (Maxver), Redes Neurais Artificiais (RNA) e Support Vector Machine (SVM). Para a imagem do satélite Landsat 5 foram utilizadas as bandas 1, 2, 3, 4, 5 e 7, e para a imagem do satélite Landsat 8 as bandas 2, 3, 4, 5, 6, 7 e 9 .

\section{Avaliação da classificação}

Para realizar a validação dos classificadores utilizaram-se amostras distintas daquelas usadas para classificação, sendo gerados os índices de Exatidão Global $(G)$, Kappa (K) e Tau (T), nas Equações 1, 2 e 3 a seguir.

$G=\frac{\sum_{i=1}^{M} n_{i i}}{N}=P_{0}$

$K=\frac{P_{0}-P_{e}}{1-P_{e}}$

$T=\frac{P_{0}-P_{r}}{1-P_{r}}$

Em que:

$n_{i i}$ : número de pixels da diagonal principal da matriz de confusão de cada classe;

$N$ : número de classes;

$P_{0}$ : concordância total ou exatidão global;

$P_{r}$ : concordância ao acaso esperada;

$P_{r}$ : concordância esperada.

Para testar a significância estatística de cada classificador e da diferença entre o Kappa dos melhores classificadores foi utilizado o teste Z (CONGALTON \& GREEN, 1998) (Equação 4).

$$
Z=\frac{K_{2}-K_{1}}{\sqrt{\sigma^{2} K_{2}+\sigma^{2} K_{1}}}
$$

Em que:

$K_{1}$ : índice Kappa da imagem 1;

$K_{2}$ : índice Kappa da imagem 2;

$\sigma^{2}$ : variância do índice Kappa (Equação 5).

$$
\sigma_{k}^{2}=\frac{1}{n}\left[\frac{\theta_{1}\left(1-\theta_{1}\right)}{\left(1-\theta_{2}\right)^{2}}+\frac{2\left(1-\theta_{1}\right)\left(2 \theta_{1} \theta_{2}-\theta_{3}\right)}{\left(1-\theta_{2}\right)^{3}}+\frac{\left(1-\theta_{1}\right)^{2}\left(\theta_{4}-4 \theta_{2}^{2}\right)}{\left(1-\theta_{2}\right)^{4}}\right]
$$




$$
\begin{aligned}
& \text { Em que: } \quad \theta_{1}=\frac{1}{X} \sum_{i=1}^{r} X_{1+} X_{1+} \quad \theta_{2}=\frac{1}{X^{2}} \sum_{i=1}^{r} X_{1+} X_{1+} \quad \theta_{3}=\frac{1}{X^{2}} \sum_{i=1}^{r} X_{i j}\left(X_{1+} X_{+1}\right) \\
& \theta_{4}=\frac{1}{X^{3}} \sum_{i=1}^{r} \sum_{j=1}^{r} X_{i j}\left(X_{j+} X_{+1}\right)^{2}
\end{aligned}
$$

\section{Análise Multitemporal}

Para a imagem classificada pelo método de classificação que obteve o melhor desempenho, foi realizada a análise multitemporal a fim de detectar as mudanças ocorridas em hectares e em porcentagem para as classes de uso da terra entre os anos de 2006 e 2015.

\section{RESULTADOS E DISCUSSÃO}

\section{Classificação de Imagens}

Os valores dos índices de concordância (Exatidão Global (G\%), Kappa e Tau) obtidos para as imagens Landsat 5 (ano de 2006) e Landsat 8 (ano de 2015) encontram-se na Tabela 1.

TABELA 1 - Desempenho da classificação por diferentes classificadores para as imagens do satélite Landsat 5 e Landsat 8.

\begin{tabular}{cccccc}
\hline Imagem & Classificador & $\mathrm{G}(\%)$ & Kappa & Tau & Ranking \\
\hline & Maxver & 91,906 & $0,890^{*}$ & 0,892 & 5 \\
& Paralelepípedo & 92,689 & $0,902^{*}$ & 0,902 & 4 \\
Landsat 5 (2006) & DM & 97,476 & $0,966^{*}$ & 0,966 & 1 \\
& RNA & 97,128 & $0,961^{*}$ & 0,962 & 2 \\
& SVM & 94,169 & $0,921^{*}$ & 0,922 & 3 \\
\hline & Maxver & 95,765 & $0,935^{*}$ & 0,943 & 4 \\
\multirow{4}{*}{ Landsat 8 (2015) } & Paralelepípedo & 84,615 & $0,762^{*}$ & 0,795 & 5 \\
& DM & 96,759 & $0,950^{*}$ & 0,956 & 2 \\
& RNA & 97,148 & $0,956^{*}$ & 0,962 & 1 \\
& SVM & 96,197 & $0,942^{*}$ & 0,949 & 3 \\
\hline
\end{tabular}

* Significativo a 95\% de probabilidade.

De acordo com a classificação de LANDIS \& KOCH (1977), os índices Kappa resultantes podem ser classificados como excelentes, com exceção do classificador paralelepípedo para a imagem do satélite Landsat 8, o qual é classificado como muito bom.

O cálculo do teste $Z$, o qual leva em consideração a variância do índice Kappa, determinou que todos os classificadores propiciaram resultados significativos, tanto para a imagem de satélite Landsat 5 quanto para 0 satélite Landsat 8.

Os classificadores de pior desempenho para ambas as imagens foram os algoritmos Paralelepípedo e Maxver, porém, ainda classificados como sendo muito bom e excelente respectivamente. Resultado semelhante foi encontrado por ANTUNES et al. (2012) que utilizaram os algoritmos Maxver e Paralelepípedo para avaliar a área de soja referente a safra de 2003/2004 e concluíram que a classificação da imagem Landsat 5 foi muito boa, alcançando Kappa acima de 0,6. MELLO et al. (2012) concluíram que a melhor classificação foi resultante do algoritmo Maxver ao compararem com os classificadores DM, mahalanobis, Paralelepípedo, isodata e k-médias para a classificação do uso da terra.

SANTOS \& MARTINS (2016), caracterizando os principais usos e cobertura do solo em uma escala temporal de dez anos, antes e após a formação do ENCICLOPÉDIA BIOSFERA, Centro Científico Conhecer - Goiânia, v.14 n.25; p. 376 
reservatório da usina de Peixe Angical no Tocantins, utilizando a classificação supervisionada com o classificador Maxver, obtiveram índice Kappa de 0,96 para o ano de 2003 e 2008, com precisão global próxima a 97\%; e para o ano de 2013 foi de 0,97 , com precisão aproximada a $98 \%$, resultados esses diferentes da presente pesquisa, a qual o classificador Maxver não propiciou resposta tão eficiente.

FEITOSA et al. (2015) analisando a estimativa da zona de deplecionamento da hidrelétrica de Balbina utilizando técnicas de sensoriamento remoto, obtiveram resultados da avaliação do desempenho do mapeamento e foi bastante satisfatório, alcançando um valor de Kappa excelente, igual a 0,95. Esses autores concluem que as técnicas utilizadas, quando aplicadas a dados multitemporais, possuem um grande potencial para o mapeamento de áreas sujeitas à inundação.

Para a imagem do satélite Landsat 5, o classificador DM foi o que apresentou melhor desempenho seguido da RNA, porém, comportamento inverso foi observado para a imagem do satélite Landsat 8 . De acordo com o teste $Z$, esses classificadores não apresentaram diferenças significativas entre si tanto para a imagem de 2006 quanto para 2015 ( $p=0,300$ e $p=0,219$, respectivamente), dessa forma, dentre esses dois algoritmos, a utilização do classificador é indiferente.

Então, o classificador DM foi selecionado para a geração do mapa de uso e ocupação da terra e posterior análise multitemporal, por ser um método relativamente simples de ser manipulado quando comparado à RNA, pois a mesma necessita de maior entendimento prévio do operador para configurações e demanda de maior tempo de processamento.

A Tabela 2 traz a matriz de mudanças da área pertencente a cada classe para os dois anos avaliados, sendo a área representada em hectare e em percentual. Nas colunas estão os valores referentes à imagem de 2006 e nas linhas a de 2015. Além disso, as mudanças ocorridas nesse período, para todas as classes, podem ser observadas espacialmente na Figura 2.

TABELA 2 - Matriz de mudanças entre os anos de 2006 a 2015 para a barragem da UHE Teles Pires para as quatro classes de ocupação do solo.

\begin{tabular}{|c|c|c|c|c|c|c|}
\hline \multirow{2}{*}{\multicolumn{2}{|c|}{ ha (\%) }} & \multicolumn{5}{|c|}{ Landsat 5 - 2006} \\
\hline & & Floresta & Água & Solo & Veg. Rasteira & Total \\
\hline \multirow{7}{*}{ 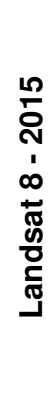 } & Floresta & $222.310,70(91,4 \%)$ & $483,21(8,2 \%)$ & $1.110,60(4,9 \%)$ & $13.287,15(26,9 \%)$ & $237.191,67$ \\
\hline & Água & $7.153,92(2,9 \%)$ & $5.174,46(88,2 \%)$ & $309,69(1,4 \%)$ & $1.371,96(2,7 \%)$ & $14.010,03$ \\
\hline & Solo & $2.402,91(1,0 \%)$ & $72,36(1,2 \%)$ & $9.667,62(43,5 \%)$ & $10.046,97(20,3 \%)$ & $22.189,86$ \\
\hline & Veg. Rasteira & $11.358,72(4,7 \%)$ & $137,52(2,3 \%)$ & $11.149,74(50,1 \%)$ & $24.740,82(50,0 \%)$ & $47.386,8$ \\
\hline & Total & $243.226,30(100 \%)$ & $5.867,55(100 \%)$ & $22.237,65$ (100\%) & $49.446,90(100 \%)$ & - \\
\hline & Mudanças & $20.915,55(8,6 \%)$ & $693,09(11,8 \%)$ & $12.570,03(56,5 \%)$ & $24.706,08(49,9 \%)$ & - \\
\hline & Diferenças & $-6.034,59(-2,5 \%)$ & $8.142,48(138,8 \%)$ & $-47,79(-0,2 \%)$ & $-2.060,10(-4,2 \%)$ & - \\
\hline
\end{tabular}




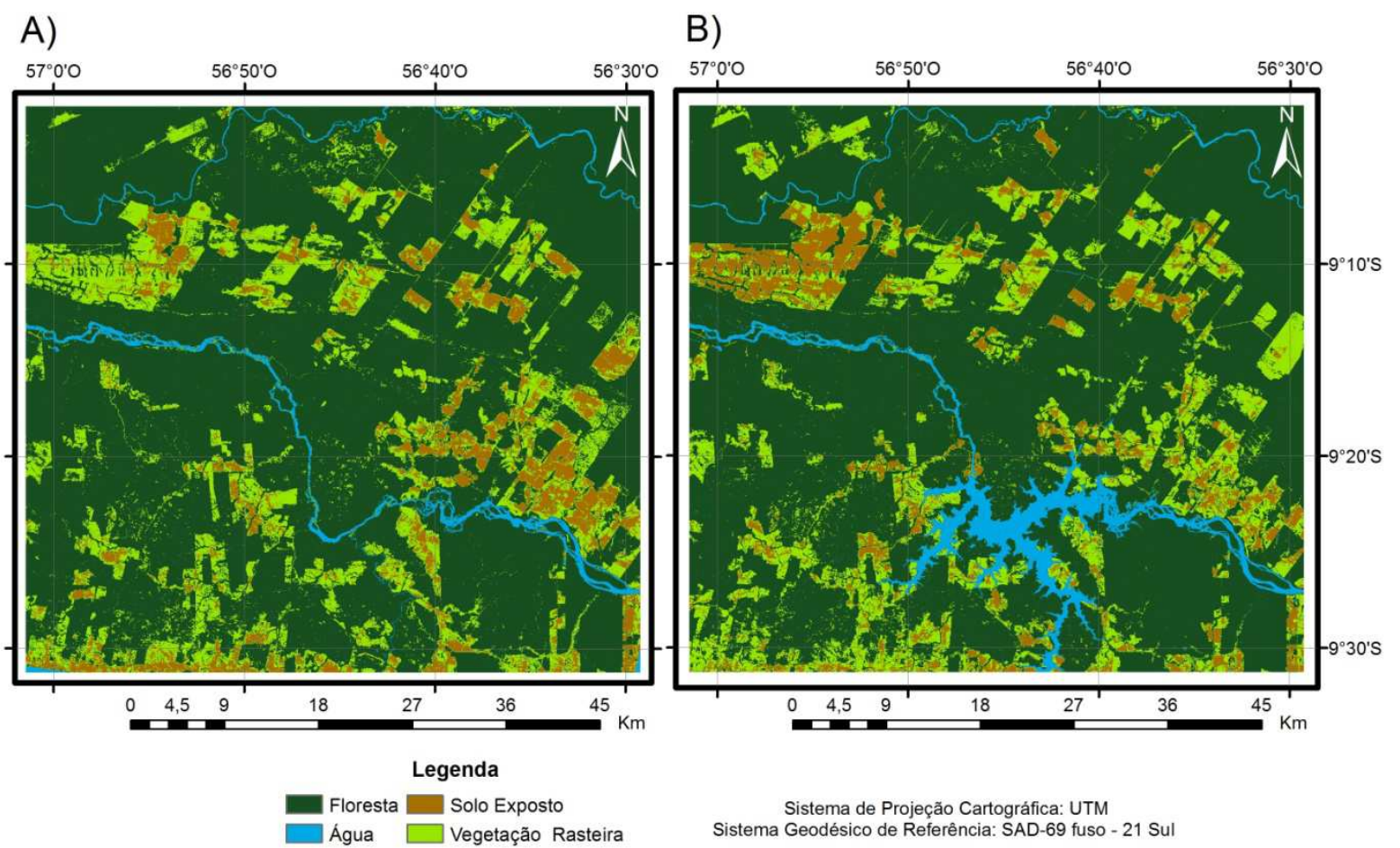

FIGURA 2 - Imagens classificadas pelo método DM dos anos de 2006 (A) e 2015 (B).

FONTE: Os autores (2016)

Observa-se que para a classe de floresta de 2006 para 2015, 91,4\% ainda correspondem a essa mesma classe; 2,9\% da área ocupada por floresta em 2006 apresentaram água em 2015, provavelmente essas áreas foram inundadas por influência da barragem da UHE Teles Pires. O montante de $1 \%$ de floresta foi convertido em solo exposto, e 4,7\% foram classificados em vegetação rasteira, provavelmente em decorrência de desmatamento e abertura de áreas para agricultura.

Para a classe de água, $88,2 \%$ da área total permaneceram nessa classe, enquanto que $8,2 \%$ foram classificadas como floresta, $1,2 \%$ solo exposto e $2,3 \%$ como vegetação rasteira de 2006 para 2015. Para a classe de solo exposto, a maior porcentagem de área que migrou de classe foi para vegetação rasteira, o que é muito natural, pois qualquer área de solo exposto, quando abandonada tende a regenerar primeiramente para vegetação rasteira; essas áreas podem também estar ocupadas por culturas agrícolas, pois esse tipo de vegetação não foi enquadrada como uma classe exclusiva podendo apresentar características semelhantes à classe de vegetação rasteira. SANTOS \& MARTINS (2016) afirmam que a identificação de áreas de solo exposto por imagens de satélite pode ser variável, pois essa identificação é dependente de data e época, ou seja, áreas que foram classificadas como solo exposto próximas a pastagens, em época de seca, podem invariavelmente representar classes de pastagens em época chuvosa.

Para a classe de vegetação rasteira, $26,9 \%$ foram classificadas como floresta em 2015, evidenciando o desenvolvimento de alguns fragmentos de vegetação nesse período. Por outro lado, $20,3 \%$ dessa área foram classificadas como solo exposto, essas mudanças podem ser consideradas normais, uma vez que essas áreas podem apresentar as oscilações das rotações das culturas agrícolas. 
Em 2015 nota-se que a área classificada como água obteve um aumento de mais de $138,8 \%$, que representa $8.142,48$ hectares, em relação à área existente em 2006, ou seja, após inundação devido à barragem da UHE Teles Pires. Dentre as áreas classificadas como outras classes em 2006, áreas com floresta foram as mais atingidas pela água da represa, pois, apesar de representar apenas 2,9\% da área com floresta inicialmente, esse percentual é composto por 7.153,92 hectares, que é um montante muito expressivo quando comparado à área inicial coberta por água (5.867,55 ha).

TRAMONTINA \& BREUNIG (2015) estudando os impactos da instalação da Usina Hidrelétrica Foz do Chapecó na divisa dos Estados de Santa Catarina e Rio Grande do Sul, através de sensoriamento remoto, constataram que a área alagada foi de $225,48 \mathrm{ha}$, representando $4,94 \%$ da área total. Desse montante, a classe de uso e ocupação do solo mais impactada devido à formação do lago foi a agricultura e pecuária, sendo que cerca de $75 \%$ da área alagada era ocupada por este tipo de uso; a classe floresta foi a segunda mais impactada, com 23,5\% da área alagada, seguido da classe solo exposto $(1,5 \%)$. Esses autores concluem que os estudos temporais do uso e cobertura da terra são imprescindíveis para a definição de políticas públicas de organização territorial, assim como, para o entendimento da dinâmica de ocupação dos territórios e como esta afeta o meio natural.

SANTOS \& MARTINS (2016) analisando em uma escala temporal de dez anos, o antes e depois da formação do reservatório da usina de Peixe Angical no Estado de Tocantins, observaram que a diminuição das áreas de vegetação natural ao longo do tempo está relacionada ao aumento de áreas de pastagens e mais explicitamente pelo alagamento provocado pela barragem. Esses autores afirmam que as ferramentas utilizadas no processamento das imagens e dos dados foram bastante precisas para obtenção das classes de uso e ocupação da terra e alertam que apesar do alto grau de preservação na região desse estudo, se fazem necessárias políticas públicas voltadas à conservação dos remanescentes de vegetação de Cerrado, garantindo a conservação das áreas ainda não alteradas.

Dessa forma, o uso de geotecnologias se mostram ferramentas importantes e eficientes para o mapeamento das alterações de uso e ocupação da terra em decorrência de impactos ambientais oriundos de ações antrópicas, como é o caso de uma UHE, e, portanto, servem de auxílio para o planejamento de recuperação de áreas, assim como de poder fiscalizador pelos órgãos públicos. Ademais, a informação do local de implantação do reservatório antes de sua operação permite identificar seus aspectos físicos iniciais e cobertura vegetal original antes do alagamento; além das atividades de uso da terra que eram comuns na bacia hidrográfica, e, deste modo, a busca do conhecimento histórico do local antes da formação do reservatório é de extrema importância para o conhecimento de seu desempenho, além de permitir verificar os principais impactos no ambiente terrestre sobre o aquático no decorrer do tempo (SANTOS et al., 2013).

\section{CONCLUSÃO}

Dentre os classificadores Maxver, Paralelepípedo, Distância Mínima, Redes Neurais artificiais e Support Vector Machine, o melhor desempenho foi resultante dos algoritmos Distância Mínima e Redes Neurais Artificiais para a área em questão. Dentre os melhores, o algoritmo Distância Mínima foi selecionado para a geração do mapa do uso e ocupação da terra por ser um classificador de fácil interpretação e necessitar de menor tempo de processamento. 
De acordo com a análise multitemporal do mapa de uso e ocupação da terra, a barragem da Usina Hidrelétrica Teles Pires inundou uma área de 8.142,48 hectares, em que a classe de ocupação do solo mais atingida era composta por floresta.

\section{AGRADECIMENTOS}

Os autores agradecem a Coordenação de Aperfeiçoamento de Pessoal de Nível Superior (CAPES) pela concessão de bolsa às primeiras autoras.

\section{REFERÊNCIAS}

ANTUNES, J. F. G.; MERCANTE, E.; ESQUERDO, J. C. D. M.; LAMPARELLI, R. A. C.; ROCHA, J. V. Estimativa de área de soja por classificação de imagens normalizada pela matrix de erros. Pesquisa Agropecuária Brasileira, v. 47, n. 9, p. 1288-1294, 2012.

CONGALTON, R. G.; GREEN, K. Assessing the accuracy of remotely sensed data: principles and practices. New York: Lewis Publishers, 1998. 137p.

FEITOSA, G.S., P.M.L.A. GRAÇA \& P.M. FEARNSIDE. Estimativa da zona de deplecionamento da hidrelétrica de Balbina por técnica de sensoriamento remoto. IN: FEARNSIDE, P. Hidrelétricas na Amazônia: impactos ambientais e sociais na tomada de decisões sobre grandes obras / Philip M. Fearnside. - Manaus: Editora do INPA, 2015. p. 127-133.

LANDIS, J.; KOCH, G. G. The measurements of agreement for categorical data. Biometrics, v.33, n.3, p.159-179, 1977.

LEITE, M. E.; DIAS, L. S.; ROCHA, A. M. Análise da ocupação no entorno da Barragem Bico da Pedra, no Município de Janaúba/MG. Caderno de Geografia, v.25, n.44, p. 221, 2015. Disponível em: <http.doi.org/10.5752/p.23182962.2015v25n.44p.221.

MELLO, A. Y. I.; ALVES, D. S.; LINHARES, C. A.; LIMA, F. B. Avaliação de técnicas de classificação digital de imagens Landsat em diferentes padrões de cobertura da terra em Rondônia. Revista Árvore, v.36, n.3, p.537-547, 2012.

MESSIAS, C. G.; FERREIRA, M. F. M.; RIBEIRO, M. B. P.; MENEZES, M. D. Análise empírica de fragilidade ambiental utilizando técnicas de geoprocessamento: o caso da área de influência da hidrelétrica do funil - MG. Revista Geonorte, Ed. Especial, v.2, n.4, p.112-125, 2012.

RIMA - UHE Teles Pires. Relatório de Impacto Ambiental da Usina Hidrelétrica Teles Pires. Empresa de Pesquisa Energética, Setembro 2010. Disponível em: < http://www.epe.gov.br/MeioAmbiente/Documents/Rimas/Rima\%20\%20UHE\%20Tele s\%20Pires.pdf>. Acesso em 28 de setembro de 2016.

ROSA DE PAULA, M. Uso de técnicas de sensoriamento remoto e geoprocessamento na caracterização do uso da terra da bacia hidrográfica da UHE Caçu - GO. Revista Geonorte, Ed. Especial, v.2, n.4, p.127-139, 2012. 
SANTOS, J. W. M. C.; OLIVEIRA, S. M. L.; SOUZA, W. P. Uso do solo e dinâmica dos nutrientes nas águas do reservatório da Hidrelétrica de Manso no Estado de Mato Grosso, Brasil Central. Revista franco-brasileira de Geografia, v.18, p. 1-22, 2013.

SANTOS, L. P. dos; MARTINS, P. T. A. Mudanças temporais no uso e cobertura do solo na bacia doreservatório de Peixe Angical, Tocantins. Ciência e Natura, v.38 n.1, p. 137 - 145, 2016. DOI:10.5902/2179-460X19073

SIQUEIRA LIMA, S. F.; TEIXEIRA BATISTA, G. Impacto da represa da Usina Hidrelétrica de Paraibuna, SP, Brasil. Ambiente \& Água, v. 5, n. 3, p. 208-221, 2010.

TRAMONTINA, J.; BREUNIG, F. M. Impacto da construção de uma usina hidrelétrica no uso e cobertura da terra: estudo da bacia Lajeado Bonito-RS. Ciência e Natura, v. 37 n.4, p. 95-106, 2015. DOI: http://dx.doi.org/105902/2179460X14404

UHE TELES PIRES. Hidrelétrica Teles Pires, energia eficiente: linha do tempo. 2016. Disponível em: www.uhetelespires.com.br/site/?page_id=184\#body>. Acesso em: 29 de set. 2016. 